\section{PSYCHOLOGY IN INDUSTRY *}

MAY SMITH, M.A., D.Sc.

Investigator to the Industrial Health Research Board

Until the present century psychology had no place in industry, for to industrialists and economists alike it was only an academic discipline not even remotely connected with life. On the other hand, since psychologists had no direct experience of industrial conditions they ignored industrial problems. Occasionally a research worker thought that his research might have an industrial application, but there was no organic relationship between the industrial problems and psychological research. $\dagger$

The industrial doctor is, however, not quite a " modern." As far back as the second century we read that Galen, before his appointment to the post of doctor to the Emperor Marcus Aurelius, was medical officer to the Roman school of gladiators-apparently they mattered. Armies in most ages have had their doctors.

The first recognition to my knowledge of industrial occupations studied seriously was when Ramazzini in the seventeenth century published a book on "the Diseases of Tradesmen." He was a professor of medicine at Modena, where it was the custom to clear out the cesspools every three years, and he was so struck with the miserable appearance of the workmen doing this that he got into conversation with them about their work; that led him to an interest in other occupations, the diseases peculiar to each, and the possible methods of treatment. He included in his list the diseases of learned men, "hoping that men of letters will not take it amiss to find themselves ranked in the class of tradesmen, considering that as they purchase to themselves by the pursuit of letters, if not great estates like those of the merchants, at least a livelihood and many comfortable conveniences. Secretaries to great men become melancholic owing to the strain of correcting their master's work and living in the uncertainty of how it would be received." Nearly two hundred years were to elapse before any further investigations were to take place. Ramazzini's book remained the standard textbook for over a century.

\section{"The Humen Machine"}

Industrial development during the nineteenth century was governed by the claims of machinery rather than of man. The enormous development of machinery during the century, the studies made in the natural sciences, and the growing knowledge of the mechanism of the body all tended to focus interest on man's likeness to a machine. The phrase "the human machine," which rightly interpreted refers to part of his structure, became, rather by implication than design, synonymous with man himself. in so far as any attempt was made to study the worker of the machine the tendency was in the direction of showing the likeness of one worker to another and the likeness of all to machines.

The problem of munition work during the great war challenged the adequacy of this point of view. Industrial operations as conducted at the beginning of that period were implicitly based on an unjustified application of arithmetic. If 6 units of work could be done in one hour then $6 \times 3$ would be done in three hours, and $6 \times 12$ in twelve hours. The physiological necessity for sleep prevented the indefinite extension of the principle. The discrepancy between the expected and the observed facts led to inquiry, and, although it was not recognized

* Part of a paper read before the Industrial Medical Officers Association at the London School of Hygiene and Tropical Medicine, January 22, 1937.

$\dagger$ In studying the effects of loss of sleep I found that among these effects were uncontrolled motor adjustments, exhibited som time after the conscious effects of fatigure had passed away; the corollary was drawn that perhaps serious accidents in such work as railway signalling might be similarly motivated. This corollary may be true, but the only way to know the facts is to examine railway signalmen. then, that stage marked an epoch in the history both of psychology and of industry. The focus of interest changed from the machine to the worker of the machine. The failure of the twelve-hour day to produce twelve times as much output as one hour, and the high sickness absence, led to the formation in 1916 of the Health of Munition Workers Committee, and after the war, under the title of the Industrial Fatigue Research Board, a small department was formed to carry on investigations into the human aspects of industrial work. The problem of fatigue, which had exercised a curious fascination over psychologists for years, proved to be the connecting link between the older and the newer study, although in spite of the voluminous literature on the subject and the innumerable experiments there proved to be little of practical applicability. The earliest investigations were concerned with the relation of the worker to the material environment-length of the working day, the duration of rest pauses, the effect of lighting, heating, and ventilation.

These investigations, although concentrating on the worker, did so relatively objectively and enabled us to get some insight into the conditions that affect numbers in a group. Certain problems, however, proved to have little or no relation to environmental or physiological conditions, the known effects of which were in some cases masked by factors relating to the mental environment and to particular characteristics of the individual workerfor example, the effect of the temperamental make-up of the people in authority and of individual workers; incentives; the suitability of the worker for his work; the effect of age and outlook ; monotony ; liability to sickness and accidents. Again the focus of interest has been shifted, and there are indications that the problems of the immediate future lie rather with studies of individuals than with groups as such, and with the mental no less than with the physical and physiological aspects. This general change is well illustrated by the history of two particular problems: $(a)$ industrial accidents, and $(b)$ telegraphists' cramp.

\section{Industrial Accidents}

As is well known the introduction of machinery on a large scale into industry had as a serious consequence numerous accidents - fatal, disabling, and slight. Efforts have been made for many years by the Home Office to reduce these by guarding machinery, but it is recognized that " however well machinery is guarded we cannot look for more than a 10 per cent. reduction in the accident rate by the provision of safeguards alone."

Any person who considers accidents in ordinary life is likely to realize that some of the so-called accidents are not quite as accidental as they would appear. He will observe that having had one accident some people are liable to be so nervous that they have more, a view embodied in the popular belief that one accident involves the victim in three. On the other hand, one accident does make some people more careful. He will also have observed that there are people, generally called clumsy, who seem to attract accidents. When two statisticians, Professor Greenwood and Mr. Udny Yule, had the curiosity to test these rival views by studying the actual accidents that occurred in large groups of people over a considerable period of time history was made. They worked out what an accident curve would look like, assuming the truth in turn of each of the above views, and although in a particular case any one hypothesis might represent the conditions, yet the one that most nearly conformed to the facts for the group was the last one-namely, that there are people who have some idiosyncrasy predisposing to a relatively high accident rate.

We are then faced with two problems: What is this idiosyncrasy? Can we by some test or tests discover the "accident prone" at an early stage? Mr. Farmer and $\mathrm{Mr}$. Chambers have been working on the second problem for years, and they can by tests select from a group those most liable to have accidents, but so far the tests would eliminate too many. 


\section{Telegraphist's Cramp}

Telegraphists who have been trained to "send" telegrams by the Morse or Baudot systems are liable to a disability that prevents them from sending effectively. This disability may be of such a nature as to interfere with most muscular activities, or it may be limited to the sending of one particular sequence of dots and dashes. The most usual explanations were that the constant delicate movements made in "keying" had resulted in chronic muscular fatigue, the cure for which would have been rest, or that some organic disease of the nerves and muscles of the arms had been set up. Neither explanation proved to fit the facts, and a detailed study of the general environmental conditions failed to find any one that was the invariable antecedent of cramp.

Attention was next turned to an experimental study of the cramp group and a group of others not so affected, with regard to neuro-muscular ability. On a priori grounds one would expect that telegraphists suffering from cramp would be less efficient than the others at all tests involving speed and accuracy of hand movements. The tests, however, failed to differentiate the two groups adequately, some of those with cramp being quite as efficient as those without. The next stage of the investigation was to find out the differences, if any, in temperamental make-up. The results showed that over 75 per cent. of the cramp group had symptoms that would lead, quite apart from the cramp, to the diagnosis of an emotional disturbance known as psychoneurotic, or in more popular language, "nervous" ; in the other group only 35 per cent. had such symptoms. Thus two investigations, conducted along different lines by different people, have certain unforeseen stages in common, leading from a study of the external and general conditions to the personal and particular. This latter investigation, involving as it did a study of nervousness, opened the way to the possibility of extending the method to other problems, of which some are:

1. What is the incidence of nervous symptoms in different groups?

2. Why in some groups does sickness absence from the socalled nervous disorders increase even in the presence of excellent material conditions?

3. In what conditions will the nervous person break down?

4. Why are some workers erratic, oscillating in output between extremes?

5. What is the effect of nervousness in people in authority and in subordinates?

6. What part is played by nervousness in industrial success and failure?

7. What are the factors, environmental and other, that protect the nervous person or determine breakdown?

Some of these have been attacked during recent years, some have been surveyed, and others cannot be attempted yet.

\section{Vocational Guidance}

Observation of individual workers shows that in particular posts some are more successful than others, whether we take an objective standard of efficiencywhere such exists-or the subjective one of personal happiness. Hence there has arisen the study known as "vocational guidance," sometimes erroneously supposed to be the same as "vocational selection." The former sets out to select for a given person the work most suited to his capacities. Theoretically this presupposes a complete knowledge of the individual concerned, a knowledge of all possible occupations and their requirements, and an ability to relate the one to the other. In practice we never approximate to this ideal.

In vocational selection we assume that the physical and mental requirements for the work are known: we then select by appropriate tests from a number of applicants those most nearly coming up to the requirements. Many firms have developed a series of tests used by them in the selection of workers. For a large number of occupations, however, the requirements are not known. What, for example, apart from the technical ones, are the qualities that make for success as a doctor? It may be that there is some one outstanding quality which some day we may be able to isolate and test ; it may be that success in the same environment may be achieved by people with very different qualities.

It is true to say that we can now, within a very narrow margin of error, test the intelligence of a child and express it in quantitative form. It is also known that certain occupations require a high degree of intelligence, whereas others do not. It is as futile to put a child of high intelligence to work needing little as to put a child of inferior intelligence to work needing a high degree. The one is wasteful, the other provokes unhappiness.

This problem, like so many others, is not of modern formulation, although it is one of modern application. At the beginning of the sixteenth century an English version of a Spanish book, Examen de Ingenios, by Huartes, was made under the title The Examination of Men's Wits. In it was made a plea for the recognition of differences of "wits," or, in modern language, intelligence, and it was suggested that in a well-ordered commonwealth men of great wisdom and knowledge should be appointed to discover each one's natural sharpness so that he might be set to learn what was most appropriate to it. Huartes also analysed the various professions from the point of view of the mental qualities required in them. He was much concerned that physicians of great learning often proved to be very bad practitioners, and he decided that theoretical medicine demands memory and understanding, but its practice imagination. Perhaps he was right.

Extravagant claims are put forward by some exponents of tests, claims which a critical scrutiny shows cannot be always substantiated, but this is not to say that they are useless. The alternatives are examination successes or a personal interview, neither of which is wholly satisfactory. Some people claim to be able to select the right person for a particular post by intuition: this seems to be all right so long as no one challenges the results. The use of tests is to give us more data on which to base a judgement, not to act as a measure to relieve us of the necessity for judgement. Ultimately in industrial selection as in the diagnosis of disease the diagnosis is an art.

\section{Differences in Temperament}

Suppose, though, that we do know the requirements for a particular activity-typing, for example-and that we have designed tests that are statistically sound and practicable to use, we have still only considered part of the problem. The actual movements or intellectual equipment that are necessary are only part of the whole. The activity has to be performed in particular circumstances and by an individual who has other characteristics in addition to those needed for typing. These circumstances and these characteristics are often of equal importance and sometimes of more importance. Let us assume that we have two typists equally efficient at typing dexterity and equally intelligent. Can we predict equal success in a given organization? One of them may be moody, resentful of criticism, irrationally antagonistic to any command, uncertain of herself, liable to worry at night over possible and even improbable mistakes: the other may be bright, reasonably careful, but able to dismiss from her mind work that can no longer be altered, easy with others, whether equals or superiors. It does not demand much knowledge to say that while the actual typing on a given occasion may be for practical purposes identical, yet the total result over a number of years will not be. The worrying over mistakes, in all probability not made, is likely to lead to real mistakes, and the chances of the first typist breaking down are more probable than those of the second. Nor will a bottle of tonic or an injunction not to worry be adequate to the situation. 
These differences, unrelated to practical efficiency or intelligence, are what we call temperamental or emotional differences. It is often not realized how complex each moment of life may be as regards possibilities of experience. For example, $\mathrm{X}$ gives a command to $\mathrm{A}$ and to $\mathrm{B}$, and he in all probability is only aware of what he wishes to have done. Rationally, too, $\mathrm{A}$ and $\mathrm{B}$ ought to consider it from that aspect and devise means for its execution. Reason is, however, rarely a decisive factor. That command, in addition, is given by $X$, and X's manner of commanding may infuriate $A$ and leave $B$ unmoved. The fringe of emotional possibilities surrounding the command is sometimes more real than the content of the command, and can be reflected in the way in which X's commands are received compared with Y's. Yet A and B may be unaware of the emotional reaction. These observations are matters of daily experience, known though usually unacknowledged, and there is no doubt that differences of temperamental nature are playing an important part in many problems of industrial efficiency, sickness absence, and labour wastage, as well as in personal happiness.

Now the person whose temperamental make-up plays a considerable part in the efficiency and happiness of an organization is the person in authority. It is obviously very difficult to study the temperaments of different people in authority and to relate them to differences in output or some other measure. Such evidence as is available has been obtained as a side issue to other investigations. There is evidence of differences of output directly connected with the temperament of the supervisor-a bright, healthy-minded person raising the quality and quantity of work. Also a high labour wastage and high sickness rates are sometimes correlated with a bully or a "Weary Willie" type.

\section{Types of People in Authority}

The following are easily differentiated: $(a)$ the emotionally disintegrated person, or in plainer language the baby; and $(b)$ the emotionally adolescent.

In the former each emotion as it is aroused is expressed regardless of consequences; the slightest crossing of his wishes results in what would be called in the nursery "tantrums." Anyone can easily wound his amour propre. He cannot bear anyone near the throne; he must be allpowerful, for not only must he have his own way but everyone must recognize that he has had it. Hence he tends to promote, in the absence of effective safeguards, weak rather than strong people, and then complains fretfully that nobody can take any responsibility. He also tends to believe in the all-powerfulness of his wishes: when, therefore, he gives an order he fails to envisage the means that often demand much time and work, so he harasses subordinates with fractious and querulous inquiries. If he has great organizing ability and the requisite physical and intellectual qualities, and the conditions are favourable, he does well-from some points of view-the very ruthlessness of the baby being an advantage. If he has poor or mediocre ability he drifts from one job to another, where there is no security of tenure: where there is, he makes the lives of subordinates miserable.

The outstanding characteristic of the emotionally adolescent is an inability to take effective responsibility. Subordinates have therefore the very difficult task of having at uncertain and irregular intervals to assume responsibility without power. Some dramatize themselves as leaders, speculate on what would happen if it were not for them, enjoy lamenting pessimistically about the state of the world in general, but seem to be unable to do what is in their power to improve their own world. To feel more sensitive than one's fellows but to be very little inconvenienced by it practically is to some people a most uplifting consolation. Such like an audience for whatever they are doing, and ride on the expressed approval of subordinates, seeing to it that they are surrounded by those who will express approval. They talk much of loyalty, which really means thinking they can do no wrong ; to criticize in any way is to be disloyal.

The common factor in these undeveloped types is that they behave according to the emotion aroused in themselves by particular circumstances, and not according to the circumstances themselves. Hence the apparent inconsistency of their conduct considered over a period of time.

What are the temperamental characteristics of the person in authority who is emotionally grown-up? This is not easy to answer. But it is certain that the successful technician can be a very indifferent supervisor of other persons. The effect of power in some people is to let loose a number of qualities otherwise held in check.

Assuming the necessary intellectual and practical equipment, I should suggest that the first requisite is a sense of justice, a capacity for asking not "Am I getting justice? " but "Am I giving it?" Where there is a feeling in an organization that all will receive a fair deal there is an excellent basis for success. Next, a capacity for sympathy, which does not mean sloppy sentimentality but the power to sense the point of view of people different from ourselves. Next, vitality, which is not mere physical exuberance but controlled energy that inspires others instead of exhausting them. Lastly, a sense of humour, preventing oneself from taking oneself too seriously.

In broad outline these are some of the problems of a psychological nature that have been referred to the Industrial Health Research Board and the London School of Hygiene and Tropical Medicine either for investigation or for advice. A study of a number of industrial failures has revealed in the majority serious psychological maladjustment. The necessity for the industrial medical officer to understand the mental as well as the physical make-up of people, and the psychological as well as the material environment, becomes more urgent each year. Some organizations can afford to employ medically qualified men and women to look after the accidents alone, but in many this is a negligible part of the work, and an infinitely greater part belongs to a different category. The problem is not whether the psychological point of view shall or shall not be taken into account; its importance is already realized by a number of organizations. The problem is whether the medical officer will be adequate to deal with it; or must it be left to others?

\section{HEALTH OF NEW YORK CITY}

In a recent communication to the Press Dr. John L. Rice, the Health Commissioner of New York, points out for the benefit of those who may contemplate visiting the World's Fair in 1939 that the city lately has had the lowest death rate for automobile accidents of the large cities of the United States. As the Fair is still two years ahead the prospective visitor might reasonably wish to be informed as to the probability of this recent low rate holding until the date of his visit. As the rate has been falling year by year, from 19.7 per 100,000 in 1929 to 12.6 last year, the time trend seems to be favourable and the prospects good.

The Commissioner draws attention also to the successful results of the intensive campaign to reduce the diphtheria mortality. In 1927 the deaths were 717 ; from that year they have declined steadily to 68 in 1935 and 37 in 1936, the last figure being equivalent to a diphtheria death rate of 2.2 per 100,000 children under 15 years of age. The number of cases of poliomyelitis was reduced to 38 in 1936; in the previous year there had been 2,054, and in 19314,138 .

Unfortunately the birth rate, too, has been steadily diminishing. In 1927 it was 19.6 ; in 1936 it was 13.4 . The Commissioner takes a serious view of this tendency, especially as the practical cessation of immigration from over-seas has already slowed the growth of the city. It is of interest that there were three deaths from tularaemia, a disease known in this country only as a laboratory infection. Wild rabbits were the probable source, and among the sick were a butcher and a cook, who had doubtless contracted the disease through dressing the carcasses. 